Revista Iberoamericana, Vol. LXXX, Núm. 246, Enero-Marzo 2014, 133-146

\title{
DEMO E SEU CONTRÁRIO: OS MANUSCRITOS DE GUIMARÃES ROSA
}

\author{
POR \\ MôNICA GAMA \\ Universidade de São Paulo
}

\begin{abstract}
Senhor sabe: Deusé definitivamente; o demoé o contrário Dele...Assimé que digo: eu, que o senhor já viu que tenho retentiva que não falta, recordo tudo da minha meninice.

Guimarães Rosa, Grande Sertão: Veredas
\end{abstract}

O que é definitivo ou não entra constantemente em choque quando estamos diante de um conjunto de manuscritos que exibem para seu leitor um movimento contínuo de permanência e questionamento do literário. Proponho neste artigo a reflexão sobre a pesquisa no acervo de manuscritos de Guimarães Rosa, assim como a observação mais atenta de um dos tipos de escrita desse conjunto, a listagem de núcleos literários que são deslocados e combinados para a construção de narrativas.

Os manuscritos de Guimarães Rosa estão conservados no Instituto de Estudos Brasileiros (IEB), na Universidade de São Paulo, desde 1979. A catalogação e a primeira organização foram coordenadas por Cecilia de Lara, assim como a orientação dos primeiros estudos que se detiveram na observação do processo de criação, com o apoio da disciplina recém-chegada ao Brasil naquela época, a crítica genética.

Múltiplo, heteróclito. O acervo de manuscritos de Guimarães Rosa é composto por rascunhos de narrativas; recortes de jornais com a crítica a sua obra; livros; desenhos; indicações para a edição de seus livros; recortes de periódicos sobre diversos assuntos; cartas, bilhetes e cartões postais; listas de palavras e expressões; diários, cadernos e cadernetas.

O estudo desses manuscritos é constantemente estimulado e questionado pela diversidade e grande dimensão do material. Cada parte do acervo que for focalizada proporcionará importantes reflexões acerca do processo de criação do escritor: a relação epistolar de Guimarães com os tradutores, por exemplo, é marcada pela contribuição generosa do escritor para encontrar as melhores opções de tradução em outras línguas, além de proporcionar uma visão do escritor discorrendo sobre suas escolhas e pesquisas. Já o conjunto de recortes de periódicos com críticas sobre a obra do escritor constitui 
um espaço privilegiado para a construção de um painel sobre a recepção das narrativas de Guimarães Rosa, preservando também as marcas de leitura do escritor em suas margens. Ao longo de diversas versões de contos publicados, pode-se encontrar alterações significaticas, tais como mudanças no rumo das narrativas ou modificações de personagens. Nas cadernetas de viagem, é possível conhecer os assuntos pelos quais o escritor se interessava e a forma que encontrou para inserir essas notas em sua literatura. Dentre outras possibilidades, o pesquisador pode tentar acompanhar o processo de escrita de um texto, articulando diversos tipos de manuscritos envolvidos nesse processo. Escolher um desses caminhos é uma ação que deixa marcas no pesquisador e dirige seu olhar para determinados pontos em detrimento de outros.

Essa pequena enumeração corre o risco de parecer óbvia em todos os estudos de crítica genética, mas quero mostrar agora que há uma singularidade na máquina ficcional de Guimarães Rosa que justifica esse deslumbramento pela imensidão de manuscritos guardados no IEB.

\section{ACUMULAÇÃO DE LITERATURA}

A aproximação com o arquivo ocorreu na ocasião em que realizei um trabalho de organização e restauro, quando pude conhecê-lo e me deparei com algumas das dificuldades que ele impõe à organização. $\mathrm{O}$ interesse recaiu nas listagens de uma das seções mais vastas, o conjunto intitulado Estudos para Obra, que é formado por 25 cadernos (com fichamentos de obras sobre pintura, literatura e filosofia, além de incontáveis listas), 7 cadernetas (em geral com anotações de viagens) e 38 pastas temáticas organizadas pelo autor, que cobrem os mais diversos assuntos. Basta citar alguns temas para se ter uma ideia da diversidade de assuntos dessas pastas: citações, arquitetura, línguas, filosofia, marinha, geologia, Homero, fauna, flora, religião, moda, costumes, música.

Essas pastas possuem sobretudo listagens de elementos registrados ou criados pelo autor. Do dicionário de botânica às artes plásticas de um museu europeu, da observação da moda nas ruas de Paris ou Hamburgo à coleta de nomes de instrumentos e ritmos musicais, diversos campos do conhecimento serviram de base para a elaboração dessas enumerações. A maior parte das palavras, expressões e/ou fragmentos de frases eram enumeradas com o símbolo $m \%$ - marca de criação ou simplesmente de apropriação de Guimarães Rosa. Tal procedimento de acumulação de discursividades parece ser determinante para a criação de efeitos nos textos.

O símbolo $m \%$ pode ser lido como meu cem por cento. A partir do estudo de Maria Celia Leonel, que pesquisou esse símbolo, é possível afirmar que essa notação se apresenta em três variantes. No registro de viagem Grande excursão a Minas, escrito em 1945, há duas formas: $\mathrm{m} /$. pode ser lido como mim (por exemplo na passagem

Revista Iberoamericana, Vol. LXXX, Núm. 246,
ISSN 0034-9631 (Impreso) 
"PAISAGEM (vista por $m /$., na viagem de jardineira)"); $m$ /. é lido como meu, de acordo com o trecho: "re-ralar $(\mathrm{m} /$.)"; e $m \%$ passa a indicar "meu cem por cento" no diário de viagem Boiada", escrito em 1952.

A forma $m \%$ é, certamente, a mais empregada. A seguir, a transcrição diplomática do trecho de uma lista (mantive usos de cores e fonte simulando a datilografia para mostrar a diferença entre ela e as passagens manuscritas a caneta azul e lápis preto):

\section{com}

Sob $\quad \mathrm{m} \%$ - exato como esquina de lampeão - ????

B. $\mathrm{C}^{\text {te. }} \mathrm{m} \%$ - fitei-o, frio. - ???

Pulso? m\% - , não é refritar almôndegas. (: não é coisa simples) - "Desenrêdo"

$\mathrm{m} \%$ - por rixa de política

$\mathrm{m} \%$ - não há dois cipós que não acabem se emendando... - H. Pinguelo

$\mathrm{m} \%$ - estabelecer um jôgo de baralho, com tôda altura

$\mathrm{m} \%$ - E tudo ia indo. - H. Pinguelo?

$\mathrm{m} \%$ - puseram môlho nêle e comeram-no

$(\mathrm{m} \%$ - um tiro no centro dos peitos, em cima do coração $)=$ Dagobés

Nesse datiloscrito, muito comum entre os que se encontram nas pastas temáticas, há 32 itens listados. Observa-se nesse trecho o cuidado do autor em deixar sinalizada a dúvida sobre a utilização por meio do uso das interrogações, assim como em grifar o que utilizou, informando o nome do texto que receberá esse $m \%$. Sabe-se por esses registros que tal lista existia, pelo menos, desde 1960, quando foi publicada a narrativa "A simples e exata história do burrinho comandante" na revista Senhor ("A estória do homem do pinguelo", da mesma revista, é publicado em 1962 e "Desenredo" no periódico Pulso, em 1965). As marcas do escritor mostram que houve diversos momentos de leitura: caneta preta e azul, lápis preto e vermelho. A lista está presente na pasta intitulada Provérbios, tema identificável em alguns dos itens, mas não em todos. Observa-se nessas listas que Guimarães Rosa recolhia a expressão e/ou palavra singular, seja por seu uso na língua, seja por uma dada sonoridade. Por isso é importante notar que o $m \%$ (meu cem por cento) é, além de uma marca de criação, um sinal de apropriação. Assim, se um neologismo é identificado pelo $m \%$, é muito comum que ele também assinale dessa forma passagens recolhidas em páginas de livros, periódicos, conversas, anúncios publicitários, entre outros.

Um dos mecanismos de criação do $m \%$ era o recolhimento ou criação a partir da leitura, sendo possível observar o recolhimento de termos das margens de livros ou de criação nas margens a partir da leitura. Para exemplificar, algumas notas feitas

1 Trata-se do diário da viagem de maio de 1952. Instituto de Estudos Brasileiros. Fundo João Guimarães Rosa, Série Estudos para Obra, Boiada I.

Revista Iberoamericana, Vol. LXXX, Núm. 246, Enero-Marzo 2014, 133-146 
pelo escritor no livro Maleita, de Lúcio Cardoso. Cabe recordar que esse é o primeiro romance de Lúcio Cardoso, de 1934, com forte traço regionalista, fornecendo muitas informações sobre Pirapora, cidade de uma região de Minas Gerais também presente nas narrativas de Guimarães Rosa.

A edição anotada e guardada por Guimarães Rosa é de 1953, e tem muitos grifos feitos com lápis preto, vermelho e azul. É comum que esses grifos estejam acompanhados de uma palavra ao lado, como se o escritor estivesse fazendo o fichamento do texto para depois encontrar trechos importantes de acordo com o tema da passagem. Assim, há notações ao lado que resumem o trecho em questão: cerrado, tropa, chapéus, anta, rio.

Mas também acontece o contrário. É o que ocorre numa página que tem, na margem superior, escrito a lápis preto: " $\mathrm{m} \%=$ plequeio de alpercata / Plequeio". Entretanto, mesmo sem nenhum trecho grifado, lê-se nessa página: "o ar trouxe o som fanhoso de uma sanfona, misturado ao pleque-pleque de sandálias em movimento" (Cardoso 19). O verbo criado e sinalizado com o $m \%$ é utilizado em Grande Sertão: Veredas: "O padre, com chapéu-de-couro prà-trasado. Só era uma procissão sensata enchendo estrada, às poeiras, com o plequeio das alpercatas, as velhas tiravam ladainha, gente cantável" (Rosa 47). Se nesse exemplo a transformação em verbo parece confirmar a ideia de que o "meu cem por cento" é uma marca de criação, observe-se o seguinte exemplo. No mesmo livro há em uma margem lateral (com lápis azul, assim como o grifo): " $\mathrm{m} \%=$ gentio". Tal palavra foi retirada da mesma página que esta passagem: "isto denunciava o sangue abominável daquele gentio, acostumado, como as feras, somente à lei da natureza" (Cardoso 96, grifo de Guimarães Rosa). O uso de "gentio" ocorre também em Grande Sertão: Veredas: "Quem tem mais dose de demo em si é índio, qualquer raça de bugre. Gente vê nação desses, para lá fundo dos gerais de Goiás, adonde tem vagarosos grandes rios, de água sempre tão clara aprazível, correndo em deita de cristal roseado... Piolho-de-Cobra se dava de sangue de gentio" (Rosa 20).

Esses dois exemplos são relativamente simples, mas significativos para entender o processo de construção dessas pequenas unidades discursivas: o espaço da margem de um livro recebe temporariamente esses termos, pois eles são transferidos posteriormente para alguma lista temática e, desde que sinalizado pelo símbolo $m \%$, é quase certo que sairá, tal qual foi anotado, para o interior de alguma narrativa. Logo, pode-se afirmar que Guimarães Rosa torna-se pesquisador de suas próprias anotações quando da realização de algum projeto de narrativa. Porém, se plequeio é um termo novo, criado por Guimarães Rosa a partir de onomatopéia presente no livro de Lúcio Cardoso, gentio é uma palavra comum, sendo mais difícil imaginar o motivo pelo qual chamou a atenção de Guimarães Rosa a ponto de receber o símbolo $m \%$.

A listagem de elementos é comum entre escritores, mas, em geral, os itens listados servem de memória para algo a ser trabalhado. No caso das listagens de $m \%$ rosianas, a enumeração é de itens prontos a serem inseridos em algum de seus textos. O escritor é,

Revista Iberoamericana, Vol. LXXX, Núm. 246,
ISSN 0034-9631 (Impreso) 
além de pesquisador, o montador de um quebra-cabeça contínuo. Por isso identifico o $m \%$ como uma célula estética: trata-se de algum elemento pronto, literário, em estado de espera do olhar de Guimarães Rosa, que vai buscar na listagem elementos que se combinem.

Dentre os diversos temas abordados na obra rosiana por Walnice Nogueira Galvão, há o texto "As listas de palavras" "que estabelece uma breve tipologia sobre essas listas a partir de um corpus de onze manuscritos, dentre eles: listas semelhantes a verbetes de dicionários, enumerações em torno do mesmo tema e também de notas de leitura, usos do $m \%$ (criação e apropriação), expressões que foram retiradas de uma narrativa e estão disponíveis novamente para o escritor. A síntese apresentada é importante para levantar a discussão sobre esse tipo de material e por notar a complexidade do material, pois, por ler essas listagens numa chave analítica que focaliza sua leitura do manuscrito na busca pela anterioridade de um texto publicado, percebe que o material não responde facilmente às hipóteses sobre a construção de uma narrativa em particular. É o que justificaria a conclusão a que chegou:

tais folhas interrogam o pesquisador, ao não estipularem - com raras exceções, como veremos -, no seu conjunto ou separadamente, alguma relação com um futuro texto. Até mesmo sua natureza de prototexto pode tornar-se discutível: apenas parte delas tem relação direta com futuros textos, enquanto outras se omitem (Galvão 155)

Mesmo que logo depois dessa afirmativa a conclusão seja a de que "a pluralidade dos materiais e sua virtual utilização exigem uma genética não estemática" (Galvão 155), a "natureza de prototexto" discutível ocorreria pela ausência de relação com os "futuros textos". Tal conclusão, no limite, não seria válida para todas as listagens rosianas, sobretudo as de $m \%$. Isso porque, mesmo sem relação com um texto publicado, tais itens estariam prontos para entrarem em narrativas, condição percebida por Walnice Nogueira Galvão quando analisa o manuscrito de itens de $m \%$ retirados do conto "Nada e a nossa condição". Tais leituras baseiam sua hipótese que "o escritor apresenta como método básico de trabalho a criação de pequenas unidades frásicas, palavras isoladas ou sintagmas, às vezes mementos para si próprio, em grande quantidade e não para o uso imediato, que ficam em latência nas listas, aguardando sua utilização" (Galvão 162). Essa formulação, resultante da análise dessa lista produzida para o conto de Primeiras Estórias, aproxima-se do que eu chamei de célula estética, mas difere-se no sentido em

2 Cito o texto em português que foi publicado no livro Mínima Mímica - Ensaios sobre Guimarães Rosa, em 2008, mas há outras duas versões do texto: "Les listes de Guimarães Rosa", de 1990, publicado no livro Penser, classer, écrire: de Pascal à Perec, assim como "Corps, lettres et listes: Guimarães Rosa à ses traducteurs", divulgado na revista Silène, do Centre de recherches en littérature et poétique comparées de Paris Ouest-Nanterre-La Défense, de 2007.

Revista Iberoamericana, Vol. LXXX, Núm. 246, Enero-Marzo 2014,
ISSN 0034-9631 (Impreso) 
que essas células estéticas existiam independentemente de um projeto de narrativa. Pela leitura dessas listagens no acervo, é possível afirmar que é muito provável a existência anterior dos itens enumerados nessa lista de elementos para o conto "Nada e a nossa condição" em outras listagens; os itens podem ter sido escolhidos nesses conjuntos e organizados nessa enumeração citada por Galvão que mostra um projeto de conto, como acontece em outros manuscritos do acervo.

O que chama muito a atenção é, para além do hábito de recolher passagens e de pesquisar em seus próprios manuscritos, o deslocamento dos termos e expressões da forma como elas se encontravam nas listas. Mas se essas células estéticas eram deslocadas de seu contexto (conversa no Itamarati ou no sertão mineiro, trecho de livro, anúncio publicitário) e inseridas em narrativas numa colagem que as mantinha da forma como foram recolhidas, pergunto qual é a consequência de um procedimento como esse para o leitor do conto que acolheu tais passagens? Se essas pequenas unidades discursivas eram inseridas literalmente em suas narrativas, supõe-se que há um respeito à identidade literária dessas passagens, pois elas já estariam prontas, já seriam literatura em pequenos pedaços. O leitor perceberia a colagem ou a origem desses elementos?

\section{A ESTRATÉGIA DOS PEDAÇOS}

Augusto de Campos (1959) observou a semelhança entre o ritmo narrativo de Joyce e de Guimarães Rosa. Para ele, ambos escreviam numa sintaxe telegráfica, "rítmica, pontuada, pontilhada de pausas". Uma ideia decorrente dessa afirmação seria a de que tal apresentação sintática obedeceria a um critério estilístico de simulação das pausas da oralidade no texto escrito. Nesse caso, haveria a simulação das pausas do discurso oral, assim como de sua flexibilidade, já que a oralidade permitiria interrupções e redirecionamentos. Em pesquisa sobre o discurso oral de Grande Sertão: Veredas, Teresinha Souto Ward (1984) observou que as recriações de palavras e de enunciados concordam com uma lógica da oralidade:

a própria separação entre as sentenças parece menos óbvia do que nos textos escritos e pausas, gestos e entonação têm um papel importantena comunicação. Das transformações usadas, o deslocamento de partes da frase é a mais pronunciada. A reorganização de elementos sugere novas relações que embora ampliando a capacidade expressiva tendem a dificultar a leitura e complicar a interpretação do texto. (54)

Logo, para Ward, a simulação da oralidade no texto ocorreria sobretudo a partir da movimentação dos componentes da frase, diluindo-a para entrar em acordo com a precariedade da fala com suas idas e vindas. Entretanto, sabendo do mecanismo de listagem de palavras e fragmentos de frases, acredito que tal ordenação frasal não é apenas produto das necessidades enunciativas. Trata-se também de uma marca do artesanato

Revista Iberoamericana, Vol. LXXX, Núm. 246,
ISSN 0034-9631 (Impreso) 
poético fundado na autoridade das pequenas unidades de enunciados.

Além disso, vale retomar que essas pequenas unidades eram, em grande parte, objeto de coleta e não de criação, o que significa dizer que se trata de citações que são apropriadas dos mais diversos espaços discursivos: o livro científico, o romance, o periódico, a conversa com alguém na Europa ou com um sertanejo. Quando de sua inserção nas narrativas, uma das consequências foi apontada no estudo sobre a oralidade de Teresinha Ward: "a aparência de continuidade e fluidez, que à primeira vista nota-se no texto, não corresponde ao seu caráter fragmentário e descontínuo que resulta em parte da incorporação de subtipos de discursos" (82-83).

É também interessante que esses subtipos de discursos das células estéticas são valorizados por Guimarães Rosa no que têm de fragmentário, desconsiderando seu caráter contínuo. Isso porque quase sempre não há a seleção de parágrafos ou mesmo de frases completas para futura reescrita ou inclusão por citação. Essas listagens abrigam partes de frases que serão combinadas a fim de encontrar um sentido - no caso de Guimarães Rosa, lacunar e paradoxal.

Oefeito poético das anotações, assim como da narrativa que recebe o item selecionado na lista, ocorre também em razão desse traço fragmentário. O fragmento, "por sua concentração e economia do discurso que mantém, o fragmento participa do silêncio ou mais de um meio-modo de dizer. Dá lugar a um modo de apreensão do mundo mais alusivo, mas um tanto sintético" (Ripoll 349).

Para observar como ocorria essa colagem de partes, apresento uma leitura sucinta do conto "Desenredo", do livro Tutaméia - Terceiras Estórias, para mostrar em seguida a presença de células estéticas e a forma como a leitura desses elementos listados agencia novos sentidos para o pesquisador dos manuscritos.

\section{A RELEITURA DO PASSADO}

"Desenredo" narra a história de amor entre Jó Joaquim e uma mulher, de nome variável (Livíria, Rivília, Irlívia ou Vilíria). Na situação inicial dessa relação, Livíria era casada e tinha Jó Joaquim como seu amante. Após ter sido surpreendida pelo marido ao traí-lo, Jó Joaquim também se descobre traído, já que esse amante não era ele. Quando ela se torna viúva, Jó Joaquim a perdoa e casam-se, mas ela se mostra mais uma vez insatisfeita com a monogamia e ele é expulsa da cidade. Entretanto, Jó Joaquim descobre ser seu amor à prova desses acontecimentos e decide inocentar a mulher frente à cidade ao recontar os acontecimentos do passado, o que consegue com sucesso, resultando na volta de Livíria e em seu perdão coletivo por parte de sua comunidade.

A narrativa é curta, contando ações de forma muito comprimida ao longo de apenas três páginas. Ao leitor não é informada a motivação para as traições e para o retorno ao relacionamento com Jó Joaquim. Também informa-se pouco sobre o perdão reiterado

\footnotetext{
Revista Iberoamericana, Vol. LXXX, Núm. 246, Enero-Marzo 2014, $133-146$ ISSN 0034-9631 (Impreso) ISSN 2154-4794 (Electrónico)
} 
de Jó Joaquim. Observe-se como é narrada a primeira vez que ele a perdoa: "Vai, pois, com a amada se encontrou - ela sutil como uma colher de chá, grude de engodos, o firme fascínio. Nela acreditou, num abrir e não fechar de ouvidos. Daí, de repente, casaramse. Alegres, sim, para feliz escândalo popular, porque forma fosse". Onde e quando se encontraram? O que ela disse ou fez para ser definida como "sutil" ou "firme fascínio"? Entretanto, mesmo sem essas informações, não há uma falha nessas ausências, pois a seleção de imagens poéticas realizada pelo escritor faz-se suficiente para a leitura.

Mesmo a tripla nomeação da amada, procedimento inesperado que rompe com as expectativas do leitor, é modificada novamente: depois da nominação variável no segundo parágrafo, a amada só será nomeada de novo no penúltimo parágrafo do texto, não mais com um dos três anteriores (Livíria, Rivília ou Irlívia), mas um outro (Vilíria). Isso porque, se Jó Joaquim reescreveu a estória da amada, um novo nome é necessário para identificar sua criação; não para apagar completamente o passado, já que é apenas mais uma formação anagramática com os mesmos elementos que as anteriores, mas para informar a mudança do rascunho contraditório que é o passado.

Rompendo com o bom senso e com o senso comum, Jó Joaquim emprega quatro significativos procedimentos para rever o passado da amada: "sem malícia, com paciência, sem insistência, principalmente. O ponto está em que o soube, de tal arte: por antipesquisas, acronologia miúda, conversinhas escudadas, remendados testemunhos" (Rosa 40). Por essa releitura inventiva do passado, o conto sugere a reflexão sobre a recepção literária, assim como sobre o processo de construção literária.

No estudo dos manuscritos de "Desenredo" não houve a motivação de buscar e descrever índices nos manuscritos (rasuras, substituições, acréscimos e deslocamentos) para a determinação temporal do que já está no manuscrito e do que ainda não foi desenvolvido; foi, antes, procurar discutir o que se deixa entrever nos manuscritos para a compreensão do funcionamento da máquina ficcional. Nesse sentido, a busca concentrou-se nas listagens de $m \%$ em pastas temáticas e cadernos com o objetivo de procurar as pequenas unidades.

Células estéticas de “Desenredo”

Mesmo sem pretender rastrear uma totalidade de trechos usados no conto, foram muitos os fragmentos de frases encontrados nas listagens, mais especificamente 44 . Desses fragmentos, apenas 13 sofreram algum tipo de modificação, tais como pequenas mudanças de ordem dos elementos na frase ou pequenas adequações (como plural ou gênero) à sentença que acolheria o elemento. A seguir, passearei por três tipos de células estéticas: as que poderiam, mas não foram inseridas no conto; as que estão em "Desenredo"; e as que já estiveram, mas foram retiradas.

Exemplifico o procedimento de transferência das células estéticas a seguir com um parágrafo do conto, destacando as passagens provenientes de listas:

$\begin{array}{llllll}\text { Revista Iberoamericana, Vol. LXXX, Núm. 246, } & \text { Enero-Marzo 2014, } & 133-146 \\ \text { ISSN 0034-9631 (Impreso) } & \text { ISSN 2154-4794 (Electrónico) }\end{array}$ 
Tudo aplaudiu e reprovou o povo, repartido. Pelo fato, Jó Joaquim sentiu-se histórico, quase criminoso, reincidente. Triste, pois que tão calado. Suas lágrimas corriam atrás dela, como formiguinhas brancas. Mas, no frágio da barca, de novo respeitado, quieto. Vá-se a camisa, que não o dela dentro. Era o seu um amor meditado, a prova de remorsos. Dedicou-se a endireitar-se. (Rosa 40)

Nesse único parágrafo foram usadas quatro células estéticas provenientes de cadernos e de páginas das pastas temáticas. No total, os $44 \mathrm{~m} \%$ usados no conto encontram-se em dez locais diferentes do acervo de manuscritos do escritor no IEB: quatro cadernos, cinco pastas temáticas e uma caderneta. É importante ressaltar que as listas não tratam de temas abordados no conto (como amor, traição, perdão, reformulação do passado ou ações inesperadas), mas sim de temas diversos, como moda, habitação, provérbios, títulos.

Além disso, tais listagens não são datadas. Na verdade, são listas que constantemente recebem novos itens e que, por vezes, têm seus elementos deslocados de uma listagem para outra. De acordo com as seleções de itens para narrativas, pode-se supor que, na época da escrita do texto em questão, a lista já existia. Logo, se numa lista existem fragmentos usados em contos de Primeiras Estórias (1962), sabe-se que a lista existia no começo da década de 1960, quando o autor começa a publicar seus contos no jornal O Globo e, logo, que existia quando da confecção de Tutaméia, a partir de 1965. Porém, esse tipo de datação não é tão confiável, pois uma lista podia existir até mesmo antes de Grande Sertão: Veredas (1956), mas não apresentar nenhuma notação de uso.

Se essa dispersão obrigava Guimarães Rosa a revisitar suas listagens como um investigador, o pesquisador dos manuscritos também acaba por atentar-se para os itens não escolhidos que estão próximos aos que entraram para a narrativa. Logo, esse tipo de manuscrito e procedimento de criação explicita uma questão deixada de lado nas pesquisas em crítica genética: o efeito estético que o próprio manuscrito pode ter sobre o leitor desses traços, seja o escritor que volta para ele em busca de elementos para suas narrativas, seja o pesquisador que busca entender ali mecanismos da criação literária. Isso porque, em nome da objetividade da reconstituição do processo, o pesquisador pode querer olhar para o conjunto de manuscritos de um escritor como se estivesse diante apenas de uma rica fonte de informações sobre a criação, deixando de atentar para o efeito que tais manobras escriturais tem sobre ele.

O tempo da leitura dessas listas age de modo singular no pesquisador. Pela grande dimensão das listagens, o leitor é levado a interpretar continuamente o tempo da escrita, imaginando se aquelas páginas que lê já teriam ou não sido escritas quando "Desenredo" começava a tomar forma. Por vezes, depois de ler dezenas de páginas sem nenhum uso nesse conto, imagina-se que ela não existia - mas, de repente, aparece um item listado que fora usado em algum dos contos de Tutaméia ou mesmo em algum dos livros anteriores. É o que acontece com o caderno 17, que contém uma grande listagem que cobre toda a sua extensão, mas que só tem expressões selecionadas para "Desenredo"

\footnotetext{
Revista Iberoamericana, Vol. LXXX, Núm. 246, Enero-Marzo 2014, 133-146 ISSN 0034-9631 (Impreso) ISSN 2154-4794 (Electrónico)
} 
nas últimas páginas. Mas também há listas que já tinham sido utilizadas em livros anteriores e que apresentavam elementos que poderiam estar no conto, sobretudo pela temática amorosa, mas que não foram selecionados.

É o caso de passagens que poderiam participar das descrições do relacionamento de Livíria e Jó Joaquim e em passagens sobre o método empregado por ele para reestruturar seu passado: "Mover dúvidas, questões - suscitar, ocasionar, levantar"; "Murou-se com uma dose de paciência, para revestir-se"; "e mutuaram-se um lance de olhos"; "namorouse dela extremosamente"3. São quatro fragmentos com conteúdo muito próximos ao do conto, seja pela forma extremosa e rápida do enamoramento, seja pelo método de mover o duvidoso através da paciência que o protegeria do passado real, mas que não são selecionados, nem de forma provisória, para a narrativa.

Mas já é tempo de abordar as frases que foram inseridas no conto. Ao encontrar essas frases, o pesquisador dos manuscritos surpreende-se ao perceber que, aquela prosódia rosiana nascida aparentemente em sua continuidade, é proveniente da pesquisa e arranjo de termos provenientes de espaços discursivos completamente diferentes. É o caso da descrição do modo como Livíria volta para o amante ("Chegou-lhe lá a notícia, onde se achava, em ignota, defendida, perfeita distância. Soube-se nua e pura. Veio sem culpa. Voltou, com dengos e fofos de bandeira ao vento"). Observe-se o contexto em que a última parte está inserida no manuscrito: ${ }^{4}$

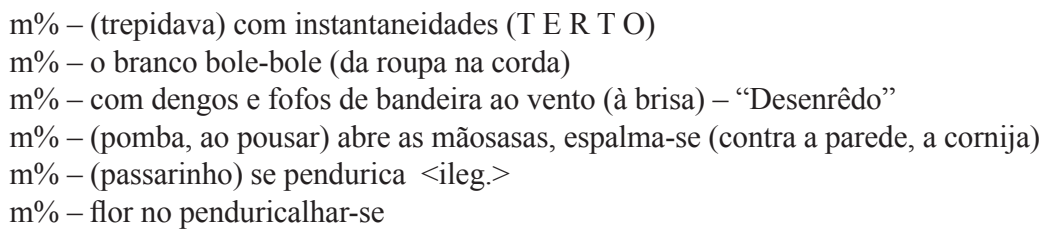

À primeira vista, pode-se pensar que há uma uniformidade temática nessa lista, pois os itens citados trazem imagens de elementos suspensos e em movimento. Mas nos outros trinta fragmentos de frases que estão nesse manuscrito há muitos outros temas:

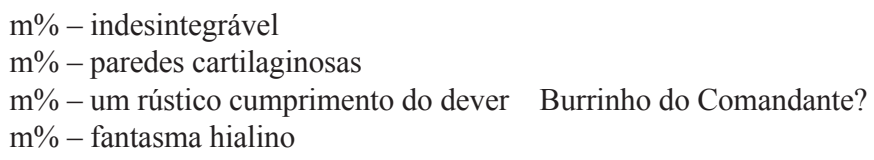

Instituto de Estudos Brasileiros. Fundo João Guimarães Rosa, Série Estudos para Obra, Cx. 11, p. 5.

4 A primeira frase está manuscrita a caneta azul e as outras estão datiloscritas também em azul com notação ao lado a lápis preto. Fundo João Guimarães Rosa, Série Estudos para Obra, Cx. 6, 1, p. 39.

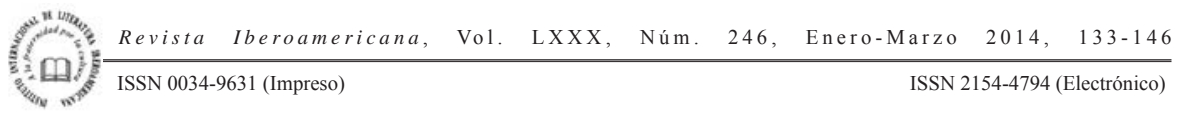


O neologismo que cria uma oposição inesperada para desintegrável antecede três expressões com adjetivações que constroem imagens imprevisíveis, mas também elaboradas com recursos comuns à língua. A partir desse breve exemplo, é possível observar como a listagem abrigava frases com temas diversos que podem passar a participar de projetos literários completamente diferentes, como acontece com o terceiro item do exemplo que foi transferido para o texto "A simples e exata história do burrinho comandante", publicado na revista Senhor, em abril de 1960 e depois no livro Estas Estórias (1969).

Entre os elementos selecionados para o conto "Desenredo", há aqueles que indicam em sua forma a maneira como devem ser inseridos na narrativa de destino: ${ }^{5}$

m \% - e a prova se irrefuta Pulso ( "Desenrêdo": e qualquer causa se irrefuta) "Desenrêdo"

O enunciado é apresentado como continuidade aditiva ou conclusiva de outro, pois inicia-se com a conjunção "e". O autor indica ainda a lápis que usou no periódico Pulso, para depois informar o nome do conto, além de preocupar-se ainda com o registro da modificação que fez para a inserção no conto - "haja o absoluto amar - e qualquer causa se irrefuta" (Rosa 40). Na modificação das palavras prova por causa oculta-se ao leitor a afirmação de um julgamento que teve provas apresentadas. Em "Desenredo" produz-se ambiguidade, pois o termo causa ainda contém uma semântica jurídica (no sentido de conjunto de interesses de alguém), mas também pode ser lido como sinônimo de motivação. Assim, está em questão não a produção e interpretação de provas, mas a afirmação de uma motivação que produza uma ação irrefutável - logo, permanece o eco de uma definição jurídica, produzindo indeterminação quando a expressão é combinada no contexto do amor que é posto como sentimento capaz de desestabilizar o conhecimento que se tinha do passado.

Se nesse caso o $m \%$ selecionado informa, em sua própria apresentação, que será a continuidade de outra ideia (uso da letra minúscula e da conjunção $e$ ), há também passagens que deverão iniciar frases:

$$
\text { m \% - (Era) infinitamente maio, "Desenrêdo" }
$$

Integrada ao momento em que os amantes se enamoram ("sorriram-se, viram-se. Era infinitamente maio e Jó Joaquim pegou o amor. Enfim, entenderam-se”), essa passagem

5 Os trechos encontram-se, respectivamente: Fundo João Guimarães Rosa, Série Estudos para Obra, Cx. 6,2, p. 9 (Datiloscrito à tinta preta); Caderno 22, p. 33 (Manuscrito em azul). A notação ao lado de todas as frases foi feita a lápis preto.

Revista Iberoamericana, Vol. LXXX, Núm. 246, Enero-Marzo 2014, $133-146$
ISSN 0034-9631 (Impreso) 
do manuscrito traz a dúvida quanto ao uso do verbo com o emprego dos parênteses, mas deixa a indicação de que seria inserida no início de uma frase, constando inclusive a vírgula ao final.

Com todo esse cuidado do escritor em informar para ele mesmo quais itens já tinham sido usados e em qual texto, há em diversos itens o uso de interrogações que mostram a dúvida sobre a inclusão, sendo possível ver casos em que o autor volta ao manuscrito apenas para apagar a interrogação quando se decide.

Porém, talvez a maior marca da importância que o autor dava para essas listagens de $m \%$ seja as listas que criava para os itens escolhidos mas que depois eram deslocados para fora da narrativa. Ou seja, quando o escritor selecionava uma célula estética e depois tirava-a da narrativa para onde tinha sido selecionada, criava uma outra lista só de passagens retiradas desse texto, nomeando-a com o título do conto antecedido por Ex ou Out.

Com o título de "Ex Desenredo", a lista datilografada consiste em 43 itens, sendo que 14 deles têm notação $m \%$. Em geral, essa lista tem as mesmas características das listagens anteriormente comentadas: traz fragmentos de frases que supõem seu modo de inserção no texto (por exemplo, estas já com a pontuação: “, por aí o que fôsse," ; "m\% -, se é que se") outras com feição de completude ("Acostumaram-se românticamente com aquilo"; "Quis fechar o coração"); outras são semelhantes a provérbios, amplamente utilizados no conto de formas imprevisíveis ("Toda boa declaração de amor consiste de anacolutos (contém))".

A lista impressiona porque leva seu leitor a imaginar onde esses itens se encaixariam no conto, acentuando ainda mais a curiosidade sobre o processo de seleção e combinação que guiou sua escrita. Muitos trechos trazem imagens tão poéticas que levam o leitor duvidar sobre as escolhas do autor, fazendo-o se perguntar por que não foram escolhidos e aceitos para as narrativas se são semelhantes esteticamente àqueles que tiveram seu espaço garantido. Nesse sentido, observe-se casos como: " $\mathrm{m} \%$ melamadurar"; "caíra nas garras do incompreensível"; "tinha-a sob olho e ferrolho" ou ainda "aprendeu a ida das idéias ao nada".

A interdição desses elementos diz respeito, em sua maioria, à produção de intederminação. Isso porque alguns dos itens listados trabalhariam para a determinação de categorias narrativas que são programaticamente indeterminadas e paradoxais. Tal procedimento altera continuamente a perspectiva do leitor ao produzir choques entre perspectivas e, logo, lugares vazios.

Isso aconteceria com a frase "Acostumaram-se românticamente com aquilo", pois ela informaria ao leitor sobre uma passagem de tempo relativa ao fato de "acostumarse". Além disso, caso essa frase se relacionasse com o modo como se encontravam

${ }_{6}$ Fundo João Guimarães Rosa, Série Estudos para Obra, Cx. 14,2 p. 22.

ISSN 0034-9631 (Impreso) 
escondidos do marido de Livíria, ela apontaria para o repertório literário dos amantes que acreditam encontrar na relação clandestina o amor procurado. O mesmo aconteceria com a passagem "Borboleta em teia-de-aranha", já que determinaria, por seus contornos, a definição de características dos amantes: Jó Joaquim seria o inocente que caíra na armadilha de Livíria. Ora, no conto, a caracterização das personagens é apenas delineada, deixando para o leitor completar as lacunas quanto ao seu caráter e meios de ação.

Quanto à descrição das ações das personagens, vale atentar para duas passagens desse manuscrito: "Sorriram-se sem fazer pontaria." e "m\% - e trocavam olhares com tolice, ao que se entrepassarem fluidos". Isso porque há nelas a descrição do modo como se enamoraram: o acaso e a inépcia guiaram um ao outro. No conto, há o enxugamento desse processo e afirma-se apenas que "sorriram-se, viram-se", ocultando ao leitor a especificação das condições envolvidas no encantamento mútuo dos amantes.

Tal tipo de elemento nessa listagem de "Ex Desenredo" parece apontar para o planejamento de uma abertura interpretativa própria da linguagem paradoxal usada por Guimarães Rosa.

\section{RELEITURA NOS MANUSCRITOS, RELEITURA DOS CONTOS: O VIGOR DO FRAGMENTO}

Quando Guimarães Rosa mantém as pequenas unidades frasais das células estéticas o autor coloca em cena a leitura fragmentária, alternando o pensamento da continuidade e da descontinuidade. Tal alternância ocorre porque o caráter alusivo e sintético da forma breve desestabiliza o sentido, levando o leitor (do manuscrito com a listagem de $\mathrm{m} \% \mathrm{e}$ o do conto) a imaginar sua origem.

A figuração do método empregado por Jó Joaquim para reescrever sua história de amor ("por antipesquisas, acronologia miúda, conversinhas escudadas, remendados testemunhos") é responsável pelo efeito de produção preparado pelo conto e recebe ressonâncias de todo o livro Tutaméia. Mas há também em "Desenredo" uma estratégia narrativa fundada nos choques de perspectivas do leitor: o que se espera da ética amorosa opõe-se à traição constantemente perdoada; o narrador que avisa o leitor que está narrando a ouvintes logo no incipit; os provérbios que nos fazem lembrar de uma forma e de uma sabedoria coletiva são reestruturados, intensificando poeticamente $o$ enunciado, mas apontam para nossa ignorância quanto às novas formas dadas a eles. Tudo isso, construído por meio de um ritmo entrecortado, "pontilhado de pausas", proveniente da colagem dessas células estéticas $(m \%)$, sugere ao leitor a reflexão sobre os modos de produção daquela narrativa.

\footnotetext{
Revista Iberoamericana, Vol. LXXX, Núm. 246, Enero-Marzo 2014, $133-146$ 


\section{REFERÊNCIAS}

Campos, Augusto de. “Um lance de “dês' do Grande Sertão”. In: Guimarães Rosa em três dimensões. São Paulo: Conselho Estadual de Cultura, Comissão de Literatura, 1970.

Cardoso, Lúcio. Maleita. Rio de Janeiro: Edições O Cruzeiro, 1953.

Galvão, Walnice Nogueira. Mínima Mímica - Ensaios sobre Guimarães Rosa. São Paulo: Companhia das Letras, 2008.

Gama, Mônica. Sobre o que não deveu caber - repetição e diferença na produção e recepção de Tutaméia. Dissertação (Mestrado). São Paulo, Universidade de São Paulo, 2008.

Instituto de Estudos Brasileiros. Universidade de São Paulo. Fundo João Guimarães Rosa, Série Estudos para Obra.

Ripoll, R. (org.) L'Écriture fragmentaire: théories et pratiques. Perpignan: Presses Universitaires de Perpignan, 2002.

Rosa, João Guimarães. Grande Sertão: Veredas. Rio de Janeiro: José Olympio, 1970. Tutaméia - Terceiras Estórias. Rio de Janeiro: José Olympio, 1967.

Ward, T. S. O discurso oral em Grande Sertão: Veredas. São Paulo: Duas Cidades / Instituto Nacional do livro, 1984.

Revista Iberoamericana, Vol. LXXX, Núm. 246, Enero-Marzo 2014, $133-146$
ISSN 0034-9631 (Impreso) 